\title{
A Literature Review on Quality Teacher's Working Life
}

\author{
Siti Intan Diyana Ishak ${ }^{1}$, Nordin Abd Razak ${ }^{2}, H$. Hussin ${ }^{1}$, Nur Suriaty Fhiri @ Daud ${ }^{1}$ and Aida Shakila Ishak ${ }^{1}$ \\ ${ }^{1}$ School of Human Development and Technocomunication, Universiti Malaysia Perlis, Perlis, Malaysia \\ ${ }^{2}$ School of Education Studies, Universiti Sains Malaysia, Penang, Malaysia
}

\begin{abstract}
Quality of work life is becoming an imperative issue to achieve the goals of the organization in every sector whether it is education, tourism, service sector, manufacturing, banking sector and other. Quality of work life it about work environment, reward, organizational commitment, recognition, participative management, work life balance, welfare facilities, proper grievances handling, job satisfaction and other. High quality of work life can give a result in better organizational performance, effectiveness and innovativeness. Quality of work life also affects the social responsibility. This is because quality of work life can improves the family life as well as work life of the individual. This paper focuses and analyse the literature review on the quality of teacher work life.justified.
\end{abstract}

\section{Introduction}

Today in many organizations, employees are not satisfied with their work. Quality of work life has become one of the organizational issues in the modern era. "Quality of Work Life (QWL)" is a human resource management concept which is used to improve the work life of employees [1].Quality of work life is the quality of relationship between employees and the total working environment, with human dimensions, technical and economic consideration [2]. [12] Believes that most studies done on the quality of work in 60 s focused on psychology of individuals and their perception of the industrial environment. Work life quality had been defined as the sum of perceived stress, or lack of stress, and perceived satisfactions, or dissatisfactions [12]. Quality of work life is the quality of relationship between employees and the total working environment, with human dimensions, technical and economic consideration [2].

Quality of work life is a process by which interest groups in the organization will learn how to work better together, how to determine for themselves what activities, changes and improvements are desirable and effective to the organization to be more efficient; as teachers at technical schools have different integration in the organization, work life and social dependence, overall living space from the other theoretical schools, thus, leading to different development of human capability and growth opportunities [3]. [5] Also points out that the concept of "quality of work life" in 80 s was a general term to include a set of conditions in different fields such as organization, work environment, and partnership. Efforts to improve the quality of life and changes healthy work environments have produced positive results not only in mental health of organizations, but also in participation rate and economic efficiency.

[13] Defined quality of work life as, "A process by which an organization responds to employee needs by developing mechanisms to allow them to share fully in making the decisions that design their lives at work". [20] Explains quality of work life in terms of eight broad conditions of employee that constitute desirable quality of work life. Fig. 1 shows the component-component of quality of work life.

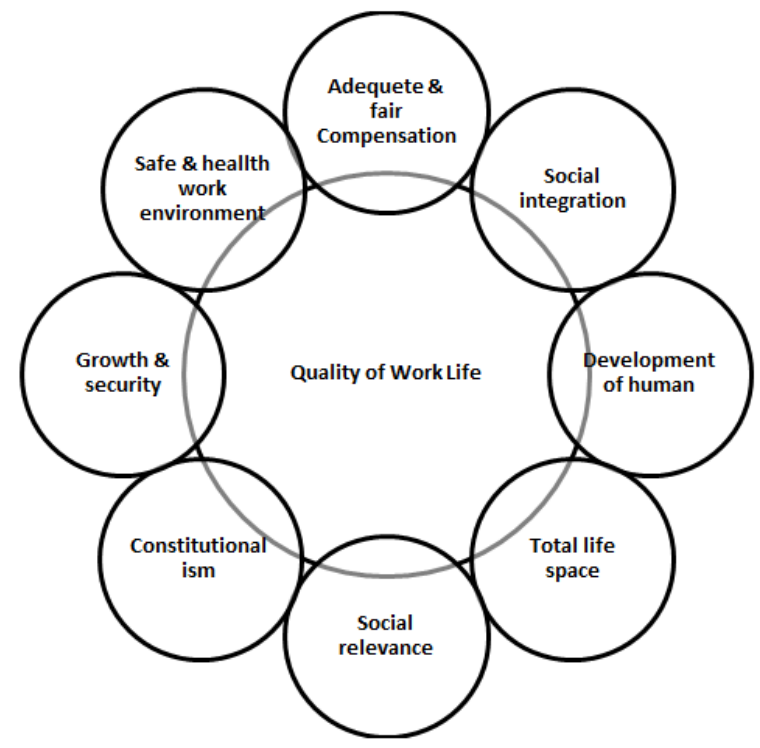

Fig. 1. Component-component in quality of work life.

Besides that, he proposed the following criteria for measuring quality of work life: 
i) Adequate and fair salary: The committee on fair salaries defined fair pay as, "the pay which is above the minimum salary below the living age".

ii) Safe and healthy working conditions: Most of the educational organizations provide safe and healthy working conditions due to humanitarian requirements and legal requirements.

iii) Opportunity to use and develop human capacities: The extents that the teacher can exercise more control over his her work, and the degree to which the teaching job embraces an entire meaningful task, but not a part of it. Further quality of work life provides for opportunities like autonomy in work and participation in planning in order to use human capabilities.

iv) Opportunity for career growth: Future opportunity for continued growth and security by expanding one's capabilities, knowledge and qualifications contributes to Quality of work life. Opportunities for promotions are limited in case of teachers either due to educational barriers or due to limited openings at the higher level.

v) Social integration in the work force: Social integration in the work force can be established by creating freedom from prejudice, supporting primary work groups to have a sense of community and inter personal openness, egalitarianism and upward mobility of teachers.

vi) Constitutionalism in the work organization: Quality of work life provides constitutional protection to the teachers only to the level of desirability as it hampers work. It happens because the educational management's action is challenged in every action and bureaucratic procedures that need to be followed at that level and is provided to employees on such matters as privacy, freedom to speak, and equity.

vii) Work and quality of life: Quality of work life provides for the balanced relationship among work, nonwork and family aspects of life. In other words family life and social life should not be strained by working hours including overtime work, work during inconvenient hours travel, transfers, and vacations.

viii) Social relevance of work: Quality of work life is concerned about the establishment of social relevance to work in a socially beneficial manner. The self-esteem work life of secondary school teachers. In the changing environment of modern technological advancement the traditional concept of the teaching profession is subjected to rapid changes. A person who enjoys the work and derives satisfaction alone can perform in the best perfect manner. The fulfillment of personal needs and goals leads to satisfaction well-being and happiness. But how far and how long could an individual be satisfied in the profession, if it is full of work related stress and strain.

\subsection{Objective of Paper}

1. To find out the scope of the quality of teacher working life in the research area.

2. To find out the dimensions used most and least under quality of teacher working life.
3. To examine the relationship between dimensions and quality of teacher working life.

\section{Methodology}

The study is based on previous research method to review literature on quality of teacher working life. The secondary data is drawn from books, journals and various reports published by the agencies working in this field.

\section{Results and Discussion}

There are only few researchers' conducted studies to analyze the quality of teachers work across the world. The researches of quality of teacher work life are shown below in chronological order: Results are taken from the research papers which have been done their research on the quality of teacher working life and their dimensions. After doing deep study of the quality of teacher working life which shows the methods of sampling, test used, respondent's rate, method for data collection, research area and findings. List of the important research paper are discussed below:

[7] Investigated effects of teacher quality of work life in secondary schools on commitment and sense of efficacy. The aim for these studied was to model that ties organizational characteristics of the work place to important behaviours, attitudes and psychological characteristics of teachers that effect their teaching is presented. Second, measures of quality of work life in eight schools are examined, along with the relationship between the quality of work life variables and measures of teachers' commitment and sense of efficacy. Finally, the effects of school structure on quality of work life are examined. The results suggested that qualities of work life measures are strongly associated with both dependent variables. The discussion focuses on the implications of the findings and the model for reform strategies.

[18] Investigated of quality of working life amongst teachers. The samples were from 100 secondary schools and 200 primary schools were selected as part of random schools in England. The findings for these studied was teachers have more job satisfaction than other workers, but are neutral about job commitment, teachers feel well supported at work and have positive working relationships with colleagues, teachers feel well supported at work and have positive working relationships with colleagues, secondary teachers would like more responsibility and involvement but primary teachers are undecided about this and Senior staff in primary schools enjoy a higher quality of working life than others in several respects, although primary head teachers feel unsupported. Besides that, teachers experience job security and are satisfied with communication in their schools, teachers are dissatisfied with their salaries and report more stress than other employees, roles and responsibilities impact on quality of working life, as do hours worked and job commitment 
is affected by levels of job satisfaction and stress in both sectors, and by levels of support in primary schools.

[8] Studied the examined relationships between quality of work life and work commitment, work stress and work satisfaction. Besides that, this study also investigated the differences in work life quality, work commitment, work stress and work satisfaction based on demographic variables and the relationships amongst the variables. This study was quantitative and conducted with 110 permanent teachers at a government secondary school in Kuching, Sarawak, Malaysia. The findings for this research were found the respondents only had moderate work life quality. Relationships between work life quality and work commitment, stress, and satisfaction also moderate but there were no differences in the quality of work life based on demographic variables but there were differences in work commitment based on gender. The results suggested that work commitment, work stress and satisfaction were not significantly correlated.

[19] Studied the perception of college teachers about quality of work life. The studied aims to help the college teachers to know the level of perception towards QWL and to enhance the same by the educational administrators. The sample for these studies was 239 . The findings were the overall quality of work life $59.0 \%$ of the respondents have high level of quality of work life and $41.0 \%$ of the respondents have low level of quality of work life. Beside that there is no significant difference between sex, type of family, age, various income levels, type of college, native place and their perceived levels of overall quality of work life. There were no significant difference between the department, type of family, the designation, the various income levels of the respondents and their perceived levels of overall quality of work life in teaching environment.

[3] Investigated to compare the rate of quality of work Life among technical and theoretical high school teachers in Kurdistan province in Iran. This studied used cluster sampling with consisted of 410 high school teachers. The data were analyzed by using descriptive and inferential statistics based on the questionnaire of quality of work Life (QWL). Findings for studied show the quality of work Life among technical and theoretical high school teachers in Kurdistan was average and there was no meaningful relationship between high school type (technical and theoretical) and quality of work life. Besides that, there were no differences in types of high schools ' QWL and all technical and theoretical high schools in Kurdistan province have the same quality of work life.

[15] Studied the relationship between quality of work life and teacher motivation among secondary school English as a foreign language (EFL) teachers in Tehran, Iran. The sample for these studied was 160 teachers and addition, 30 of the participants were randomly selected to take part in follow-up interviews which asked why they felt the way they reported. The findings revealed that the participants enjoyed a medium level of quality of work life and experienced a mediumto-low level of motivation and a significant relationship was found between motivation and quality of work life categories. Meanwhile, the subscales of the quality of work life that best predicted teacher motivation were identified.

[9] Investigated the quality of work life for secondary school teachers from Mysore City. This studied used adopting stratified random sampling technique and the sample was 100 teachers. Besides that this studied was adopted the descriptive survey method. The results of this studied were a majority (70.2\%) of the secondary school teachers in Mysore was found to possess an average level of quality of work life and $(13.9 \%)$ were found to possess low level of quality of work life and only (15.9\%) of the teachers possessed high level of quality of work life. There was significance difference of Quality of Work life of male and female secondary school teachers comparing teachers mean scores it is found that the female teachers have a high quality of work life than their male counterparts. Meanwhile there was no significance difference between above 10 years' experience and below 10 years of experienced secondary school teachers in their Quality of Work Life and no significant difference is the quality of work life of teachers belonging to government, private aided, and private unaided secondary school teachers.

[10] Investigated the assessing the quality of work life and its components the primary school teachers of the Isfahan city. The population was composed of 862 teachers in Isfahan and 120 Samples were selected based on statistical estimates and simple random sampling. The results for these studied were the quality of life of teachers is less than average. Its means they do not enjoy the good quality of life. However, the desire and motivation to the teachers was high but component of the salary of the teachers had the greatest dissatisfaction. The results indicate that female teachers have the higher quality of life than male teachers. Beside that studied shows the results also suggest that there is no difference between single and married teachers' comments on the quality of work life. Results also show that there is no difference between the views of teachers with less than a bachelor's degree and bachelor's degree or higher in about the quality of work life and its components.

[16] The studied explore various dimensions of quality of work-life (QWL) as it affects the life and attitude at work of teachers of private universities in Lahore, Pakistan. This study was quantitative and conducted with 360 faculty members from private universities in Lahore, in order to find out their perceptions of QWL, and its spill-over effect on employee commitment, engagement, job involvement and reputation of the university. The findings for this research was found that perceived value of work, work climate, work-life balance and satisfaction with relationships in life were the major factors which shaped work attitudes and employee perceptions of overall quality of work-life. The research was carried out in order to discover how teachers in private universities in Pakistan view their work environment and whether this working environment is helping them to become valued human beings or not. Besides that this research makes two contributions, scholarly and practical. The scholarly contribution highlights that the dominant constructs of 
QWL play an important role in shaping attitudes towards work, life and relationships of teachers of private universities. On a practical level, the study hints at the possible implications of dissatisfaction and imbalance within employee commitment and engagement, and even the reputation of the university.

[11] Investigated quality of work life of employees in private technical institutions. These studied helps the technical institution employees to know the level of perception towards quality of work life and to enhance the same by the management. The sample consists of 109 employees of a technical institution the results reveals that male employees are more satisfied than female employees. Beside that there are no significance relationship between demographic characteristics of employees and quality of work life. These studied also reveals that Adequacy of Resources are more correlated and Training \& Development are less correlated with QWL in teaching staffs and in case of non-teaching staffs compensation \& rewards are more correlated and work environment are less correlated with QWL. Furthermore the correlation analysis also reveals that all the dimensions of QWL are positively correlated with QWL of faculties, which indicates that enhancement in the dimensions of QWL, can lead to increase the overall QWL of faculties.

[4] Studied explored about perceived factors that influence teachers' quality of work life in primary schools in one education district in Trinidad and Tobago. Beside that's to develop separate Quality of Work-life (QWL) categories and make comparisons among schools. The sample for these studied consisted of randomly selected 405 teachers from thirty (30) government and assisted schools primary schools from the St. George Education taking into account variables such as size, school type, demography and sex. Furthermore studied also examined the relationship between the demographic and school-level quality of work life factors as well as the predictive power of each independent factor on overall quality of work life. These studied was quantitative method using a cross-sectional design. The findings indicated further that there was a moderate to high correlation among the quality of work life factors and collegial relations among teachers had the greatest influence on their work life in school.

\section{Conclusion}

After the study of literature review on quality of teacher work life, it is clear out that an education organization cannot get efficiently and effectively outcomes from the employees' without quality of work life. Quality work life is the shared responsibility not only of the management and employees, but also by the society.

To improve quality of teacher work life is first to identify and then try to satisfy employee's important needs through their experience in their working environment. Depending upon the situational requirements, management may select the relevant needs of the employee's to improve them with a short term plan. There is a significant association between quality of work life total and quality of life in teaching environment total.

[6] It can be conclude that most research of QWL has done on the academic section which showed faculty relations and community services is the most positive elements in faculty's work life and in present scenario highly satisfaction in the female regarding QWL dimensions compared to male. The purpose of this paper was to find out the important dimensions of quality of teacher work life from literature review. More than 25 literatures were investigated out of that 11 literatures discussed deeply and the most extracted factors were gauged. The aims of the paper to find out the variable are affect the quality of teacher work life in the researcher life. The finding shows that there are some dimension been used frequently in the literature rather than other dimension. Table 1 is shows the variables are used in most researchers.

Table 1. Variable used in research quality of teacher work life

\begin{tabular}{|l|l|l|}
\hline Extremely Used & Average Used & Least Used \\
\hline Job satisfaction & Social & Delegation of \\
Demographic & integration & authority \\
factor & Attitude and & Organization \\
Pay and benefits & perception & citizenship \\
Supervision & Employee & behavior \\
Organization & participation & Training and \\
commitment & Work life & development \\
Growth and & balance and & Financial ratio \\
development & relationship & Equal job \\
Safety and & Rewards & opportunities \\
healthy & Team work & \\
environment & Welfare and & \\
& opportunities & \\
& Autonomy & \\
\hline
\end{tabular}

\section{Suggestions}

This paper only focuses in quality of teachers work life in the research area, the dimensions used in most under quality of work life and the relationship between dimensions and quality of teachers work life. The convey further researchers who are interested to do research on quality of teachers work life and having a confusion how to relate a quality of teachers work life with their dimensions because there have been done more research on quality of work life and their variables. Besides that, further researchers also can refine the definition of quality of work life.

There are some dimensions such as such as team work, attitude and perception, pay and benefits, social integration, participative management, organization commitment, growth and development, job satisfaction, , safety and healthy environment and participative management, salary, employee participation, welfare opportunities, rewards are have been used by mostly researchers continuously. There are many dimensions still untouched which affect quality of work life such as growth and profitability of organization, organization citizenship behaviour and personality. 


\section{References}

1. P. Archana, B.K. Jha, Global Journal of Management and Business Research: A Administration and Management 14 (11), (2014)

2. A.F. Chelte, Organizational commitment, job satisfaction and quality of work life. U.M.I. (1983)

3. H. Farideh, M. Bahram, International Journal of Vocational and Technical Education 4(1), 1-5 (2012)

4. G. George, International Journal of Humanities Social Sciences and Education (IJHSSE) 1(10), (2014)

5. J. Huzzard, The Convergence of the Quality of Working Life and Competitiveness: A Current Swedish Literature Review(National Institute for Working Life, Stockholm, 2003)

6. L.K. Johnsrud, Studied on Quality of faculty work life ( the University of Hawaii, 2006)

7. L.S. Karen, Effects of Teacher Quality of Work Life in Secondary Schools on Commitment and Sense of Efficacy. School Effectiveness and School Improvement 9(1), 1-27 (1998)

8. S.H. Kian, W.T. Kok, B. Suriani, Technology Journal 1-15 (2010)

9. N.D. Manju, International Journal of Education and Psychological Research 3(2), (2014)

10. E. Mohammad Kazem, K. Mahnaz, N. Fateme, Interdisciplinary Journal of Contemporary Research in Business 3 (9), (2012)

11. T.S. Nanjundeswaraswamy, D.R. Swamy, Management Science Letters, 5(1), 65-78 (2015)

12. D.M. Pelsma, G.V. Richard, R. G. Harrington, J.M. Burry. 1989. Measurement \& Evaluation in Counseling \& Development 21(4), 165-176 (1989)

13. S.P. Robbins, Organizational behaviour Concepts, controversies, applications (New Delhi: PrenticeHall of India Private Limited, 1999)

14. G.M. Reyan, Theoretical basic for the QWL concept (University of Siena, 1995)

15. B. Sasan, G. Yahya, Australian Journal of Teacher Education 37(7), (2012)

16. A. Seema, I. Maryam, Quality Assurance in Education 21 (3), 282 - 298 (2013)

17. A. Shirkovand, Studied the relation between the quality of working. life and performance of insurance Company in Tehran (Tehran: Allameh, 2007)

18. L. Sturman, (2003). Survey of Quality of Working life in Teachers. Retrieved from http://www.nfev.ac.uk/research-areas/pims-data/sum

19. B.P. Subburethina, M. Umaselvi, K.N. Senthil, Quality of work life: Perception of college teachers (Hallamark Business School, Trichy, Tamilnadu, India, Majan,University College, Muscat, Sultanate of Oman, Anna University Chennai, 2010)

20. R.E. Walton, Improving the quality of work life (Harvard Business Review, 1974) 